\title{
Studying Formability Limits By Combining Conventional and Incremental Sheet Forming Process
}

\author{
Fabio Andre Lora ${ }^{1}$, Daniel Fritzen ${ }^{2}$, Ricardo Alves de Sousa ${ }^{3^{*}}$ (D) and Lirio Schaffer ${ }^{4}$
}

\begin{abstract}
In this work it is assessed the potential of combining conventional and incremental sheet forming processes in a same sheet of metal. This so-called hybrid forming approach is performed through the manufacture of a pre-forming by conventional forming, followed by incremental sheet forming. The main objective is analyzing strain evolution. The pre-forming induced in the conventional forming stage will determine the strain paths, directly influencing the strains produced by the incremental process. To conduct the study, in the conventional processes, strains were imposed in three different ways with distinct true strains. At the incremental stage, the pyramid strategy was adopted with different wall slopes. From the experiments, the true strains and the final geometries were analyzed. Numerical simulation was also employed for the sake of comparison and correlation with the measured data. It could be observed that single-stretch pre-strain was directly proportional to the maximum incremental strains achieved, whereas samples subjected to biaxial pre-strain influenced the formability according to the degree of pre-strain applied. Pre-strain driven by the prior deep-drawing operation did not result, in this particular geometry, in increased formability.
\end{abstract}

Keywords: Hybrid forming process, Incremental sheet forming, Strain paths, Numerical simulation

\section{Introduction}

Incremental Sheet Forming (ISF) has been intensively studied over the last years. Since the patent from Lezsak [1], CNC development allowed to many improvements in terms of materials, geometries and design possibilities. The pivotal work from Jeswiet et al. [2] set the basis for all the major developments during this century, whereas the state-of-art and future developments were updated by Behera et al. [3]. The ISF process aims to produce small batches of parts, fast prototyping and personalized products giving flexibility with inexpensive operating costs. The cost reduction comes from the absence of dedicated tooling, such as punch and die. The ISF is generally performed by clamping a sheet all over its borders

\footnotetext{
*Correspondence: rsousa@ua.pt

${ }^{3}$ Center of Mechanical Technology and Automation, Department of Mechanical Engineering, University of Aveiro, 3810-193 Aveiro, Portugal Full list of author information is available at the end of the article
}

and through the punctual application of a local load over the sheet metal, performing repeated strains in the form of a descending contour that shapes the final geometry. This simplest variant of ISF is called Single Point Incremental Forming (SPIF). Drawbacks reported are related to higher forming times and difficulties to form vertical walls.

Regarding formability for SPIF solely based forming processes, many authors claimed and proved that formability under any incremental process is higher than in conventional press-based sheet forming. References [4-12] are few examples of studies focusing of different materials (aluminium, brass, high-strength steels), deformation mechanics or methods to evaluate formability. Under conventional stamping operations, the blank is considered subjected to an in-plane and bending deformation state leading to the onset of necking. However, the deformation mechanisms on ISF process are still a doubtful topic between different research groups, being 
generally accepted that the necking phenomenon is widespreadly present on the sheet prior to fracture. It can be stated that a sheet metal forming processes is limited to the maximum, strain achieved prior to fracture. The most usual methods to define the formability limit is the Forming Limit Diagram (FLD) or Forming Limit Curve (FLC). They are obtained plotting the major principal strain and minor principal strain differentiating the safe (no rupture) from failure (rupture) zones. These graphs are generally experimentally established, giving the values of major and minor principal strains for countless loading configurations like equi-biaxial, biaxial, plane strain or uniaxial. Figure 1 depicts a schematic comparison between the FLC for a stamping and incremental forming.

The SPIF processing limit must be derived in terms of fracture onset [11], which usually results a straight line with a negative slope in the positive region of minor strain (also called as FFL, Fracture Forming Line), whereas the conventional stamping is presented in both regions with minor strain. Distinct effects may derive from chosen tool type, tool size, vertical pitch size, feed rate, friction at the interface contact of tool/sheet surface and plane-anisotropy of sheet $[11,13]$.

Another common indicator for formability in ISF processes can be obtained using the maximum achievable forming wall angle, Figure 2. Ham and Jeswiet [14] examined several SPIF variables (feed rate, step down, etc.), as well as materials, and the resulting influence on the maximum achievable wall angle. Fritzen et al. [6] studied it for Brass alloys while Bastos et al. [9] for high strength dualphase steels. The fact that all ISF process variants (SPIF,

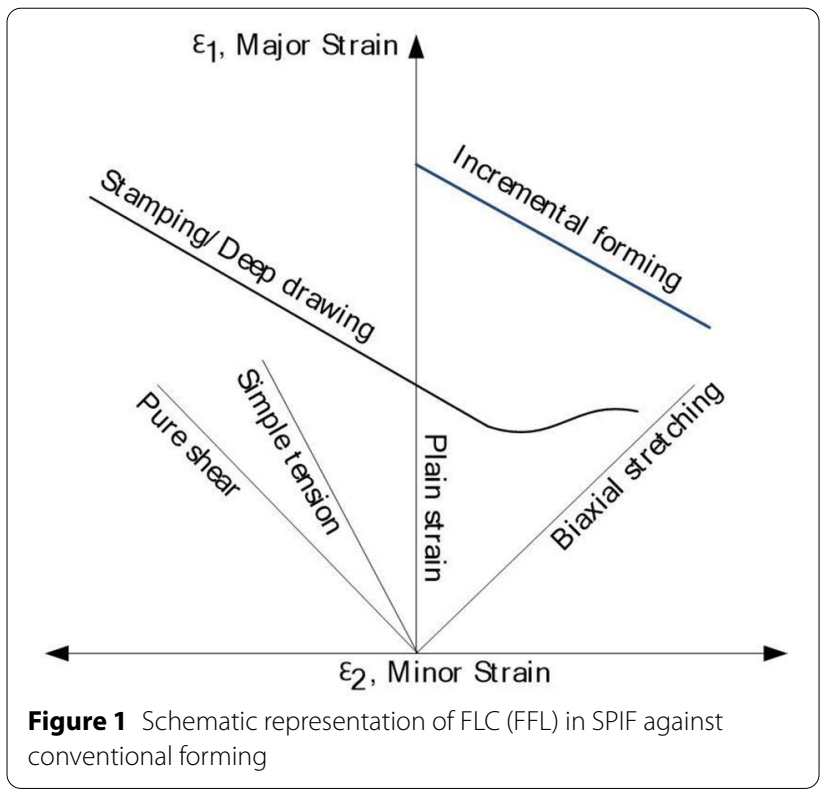

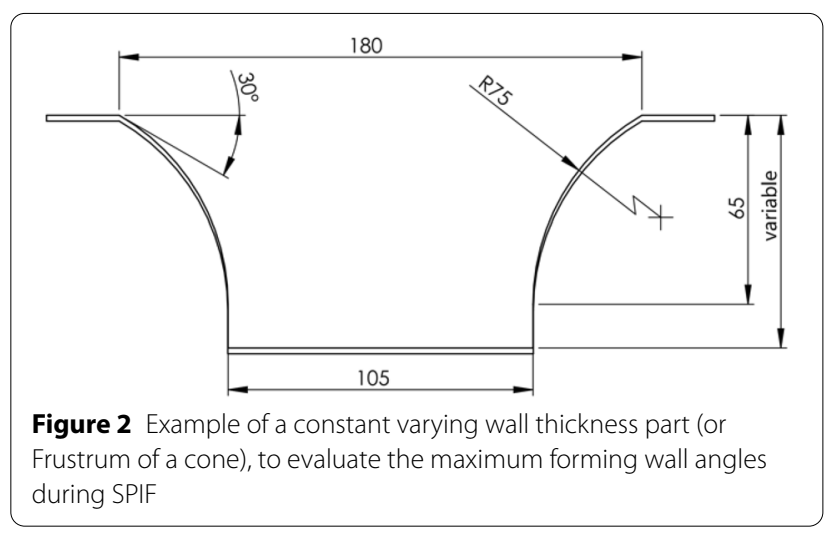

TPIF, etc.) induce localized deformation is the primary leading to a deformation mechanism that act as local stabilizers before fracture. So, fracture in SPIF occurs with generalized, diffused necking all over the part. Emmens and Van den Boogaard [15] have presented a pivotal review of possible deformation mechanisms, giving feasible reasons that can possibly explain the enhanced formability in ISF processes. Among them: contact stress, bending-under-tension, stretching, shearing, cyclic loading, necking stabilization and hydrostatic pressure. They argued that a single deformation mechanism cannot be regarded as being the main one. In fact, every analysis is depending on the geometry, process parameters and toolpath.

Hybrid forming processes, as posed by Araghi et al. [31], have true potential by employing the combination of ISF and stretch forming, by reducing processing time, providing more uniform strain distribution and easier numerical simulation. In this work, the presence of a pre-strain derived from a previous forming process is investigated. There are several cases where ISF technology might be applied in a deep-drawn component, for instance for personalization purposes [16]. The combination of forming processes, namely conventional drawing before incremental, falls on the category of the so-called hybrid forming process. The application of both processes may lead to achieve greater strains and improve formability in metallic materials by a careful choice of pre-strain and strain paths on both stages. Studies [1719] have shown the developments of the hybrid process of stretch forming and incremental sheet forming. These works were based on the application of the stretch forming process and subsequent application of incremental sheet forming in the manufacture of complex details of the workpieces.

This study aimed to evaluate the behavior of the strains occurred in the samples of EN10130 DC04 steel, formed through a hybrid forming process. The effect of 
pre-strains coming a sequence of conventional forming on a subsequent incremental forming process (in terms of formability) is still not well-documented. Doing so, the present contribution aims to fill this gap on the literature. The numerical simulation will then be performed using a finite element package to determine the parameters of the processes and compare them against the measured results.

\section{Materials and Methods}

During the conventional press-forming operation, strains are generally evaluated using Forming Limit Diagrams (FLD's), in combination sometimes with a Forming Limit Curve (FLC) as a failure criterion during sheet metal forming process. In what regards ISF operations, the particular deformation mechanics during the process makes FLD's not suitable to characterize the formability limits, mainly because the limiting strains in the principal strain space significantly exceed the FLC [20-24], and additionally because the strain-path in ISF processes may be highly non-linear. Toolpath optimization is actually nowadays one of the main topics in ISF studies [3].

The hybrid process developed in this work was set according to Figure 3. The stages of the stretch forming process and the asymmetric incremental sheet forming (AISF) are combined as shown in Figure 3(a), 3(b) and 3(c) sequentially. Besides increasing formability, the process combination aims to increase the dimensional accuracy compared to single AISF $[25,26]$.

\subsection{Numerical Simulation}

Numerical simulation allowed for determining the dimensions of the test specimen and determination of the correlation of the strain paths of the core elements throughout the process. In incremental sheet metal forming, different incremental strategies have been analyzed in order to reach ruptures in the samples. Finally, after the physical experiments, the numerical simulation was used to compare with the measured data from hybrid process strains.

Because incremental forming is a progressive sheet metal manufacturing process characterized by large displacements and large total strains, the explicit solution scheme should be adopted to save CPU time [27]. Under LS-Dyna explicit solver, the Barlat 36 model, based on the work of Barlat and Lian [28] was employed. It was developed to model sheets with anisotropic materials under plane stress conditions. Also, this material model allows the use of the Lankford parameters for the definition of the anisotropy. The constitutive parameters used for the numerical simulation are shown in Table 1.

The blank holder, punch and die were assumed as rigid. A Coulomb model was considered for the frictional $(\mu=0.1)$ actions, which is a typical value found in literature for lubricated SPIF processes. The mesh was 2 $\mathrm{mm} \times 2 \mathrm{~mm}$ quadratic with three-degree remeshing. A four-node linear Belytschko-Tsay shell element with 3 integration points through thickness direction was used. Three integration points is the minimum required number to provide a non-linear computation of the throughthickness stress while keeping maximum CPU efficiency for the shell-based simulation. Despite the limitations of shell elements regarding thickness variation prediction [29], this finite element is widely recognized for the reliability avoiding pathologies like locking phenomena or hourglassing. The exponent $(\mathrm{m})$ in the Barlat yield surface was 6.0, and the plastic yield expressed using the Hollomon formula is described in Table 1.

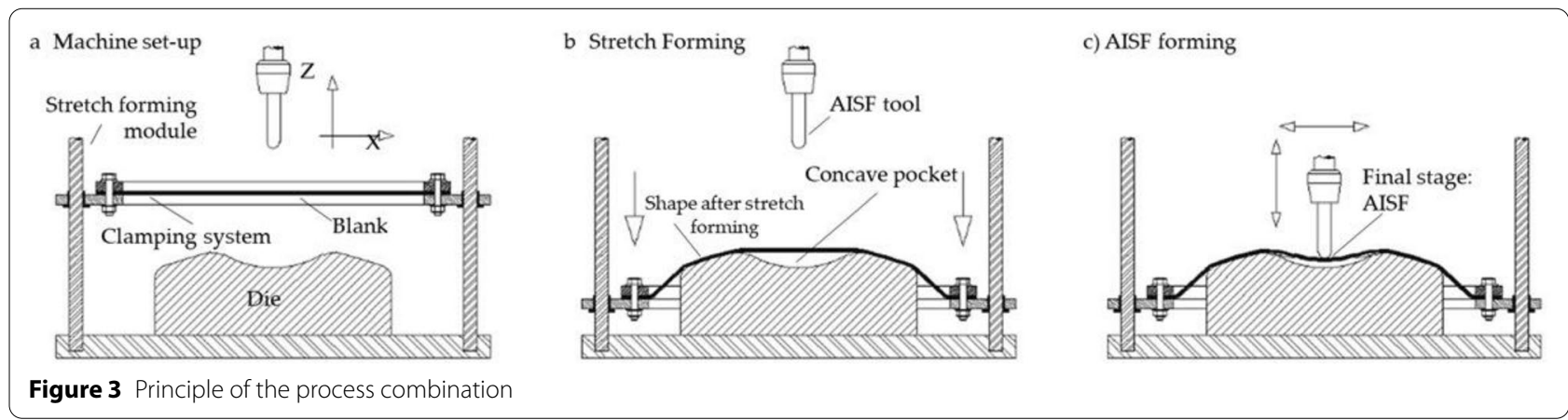

Table 1 DC04 material data

\begin{tabular}{|c|c|c|c|c|c|c|}
\hline Hollomon formula & Yield stress & Anisotropy & & & & \\
\hline$k f=564 \cdot \varphi^{0,2}$ & $k f_{0}=186 \mathrm{MPa}$ & $r_{0^{\circ}}=1.16$ & $r_{45^{\circ}}=1.52$ & $r_{90^{\circ}}=1.69$ & $r_{m}=1.47$ & $\Delta r=-0.09$ \\
\hline
\end{tabular}


During stretch forming, the Forming Limit Diagram was applied as failure criteria. Data is obtained from the work of Lora [30]. The incremental forming phase was stopped using the average depth from each experimental test. The computational simulation was stopped after reaching the preset depth.

\subsection{Experimental Campaign}

For the experiments, a hydraulic press and a specific machine (Amino, model DLNC-RB) for the incremental sheet process were used. Figure 4 shows the schematics of tooling for both pieces of equipment.

The hybrid sheet forming process, described in this paper, was divided into two parts: the numerical simulation of process, and the physical experiment, by stretch forming and incremental sheet forming. Numerical simulation (as carried out in the previous section) was employed to estimate the dimensions of the test specimen and to determine the correlation of the strain paths of the core elements during the process, as well as in the incremental sheet metal forming stage.

\subsubsection{Conventional Forming}

The conventional forming process occurs through the pressure applied by a large punch over sheet metal. This punch has smaller dimensions than the sheet, while being much larger than the ISF tool.

Because the conventional process has constant velocity, due to the hydraulic press used, and no interruptions, the strain evolution on some sheet areas is quasi-linear. This evolution is characterized by the forming path, which does not reveal any intersections or severe changes in direction. Figure 5 shows two distinct forming paths for the separate elements in the same simulated sample.

According to Figure 5, performing the conventional process in a single stage applies constant forming paths in the sheet metal at the top part of the sample and at the side wall. The major true strain can also be traced relative to the punch/die displacement, i.e., the process strain path. The digital image correlation system ARAMIS (GOM, Germany) was employed to keep track of deformation patterns over the formed sheets. Figure 6 shows the major true strain path over the time for element " $\mathrm{A}$ " in Figure 5.
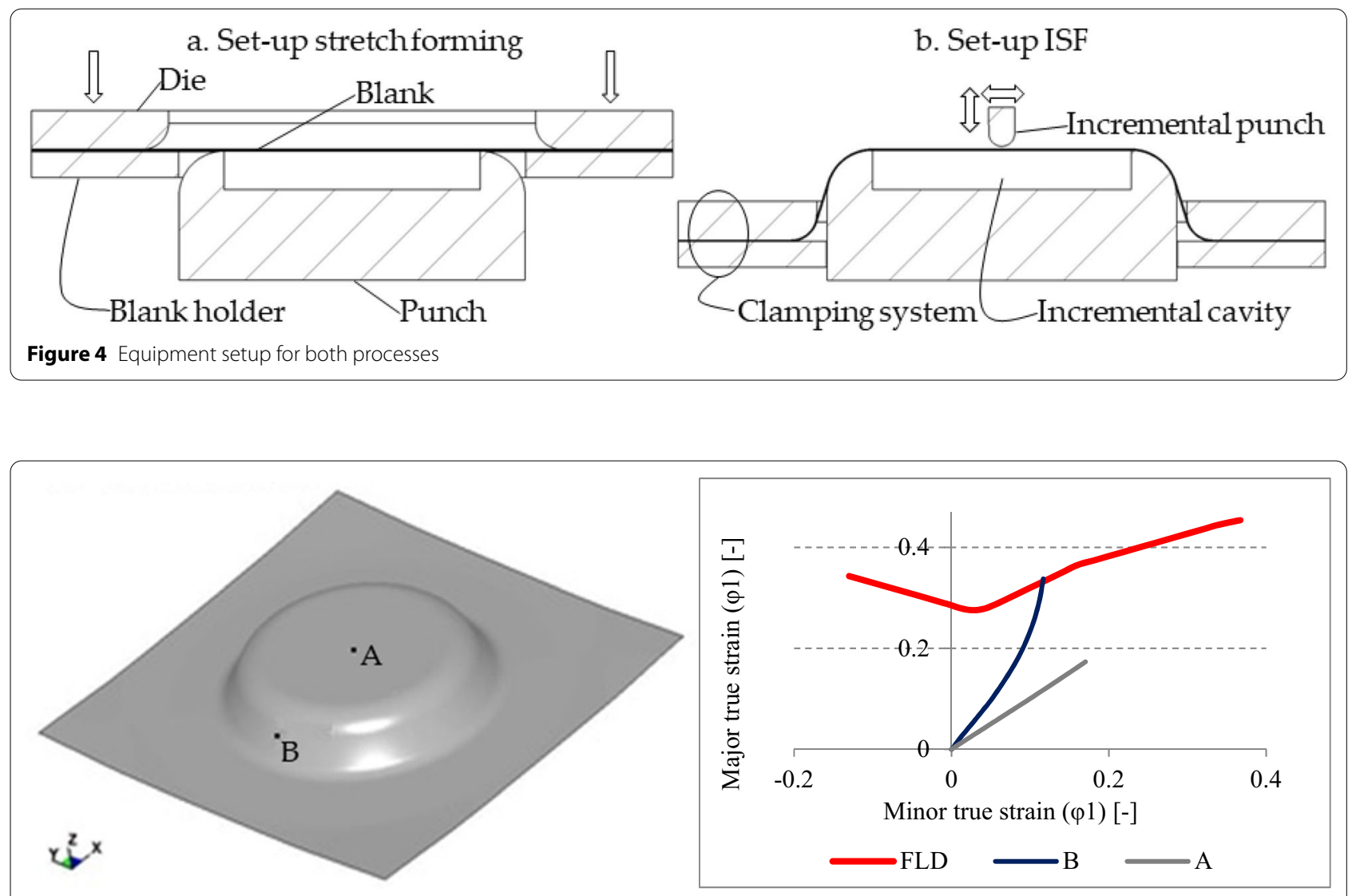

Figure 5 Forming paths for different elements of a formed sample. FLD from work [30] 


\section{Major strain curve over the time}

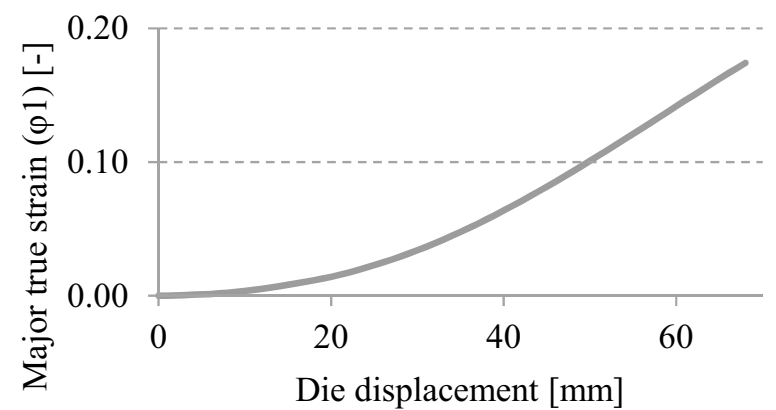

Figure 6 Strain path over the time

Figure 6 shows that the strain path during process is not fully linear; it cannot be applied in a linear relationship relatively to the die position with instantaneous strain. The central element of the workpiece (element "A" from Figure 5) was selected as the stop criteria during the experiments.

The tests were carried out using DC04 $1 \mathrm{~mm}$ thick sheets, with length $=500 \mathrm{~mm}$ and three distinct widths: 200, 330 and $500 \mathrm{~mm}$. The lubricant used is a white assembly paste (OKS 260), whereas the blank holder force was set to $300 \mathrm{kN}$; die displacement velocity was set to $3 \mathrm{~mm} / \mathrm{s}$ while its displacement (depth) was predetermined relatively to the major true strain.

The conventional process trials were carried out following four stages. They were chosen by dividing the different die penetration depths. The criterion used to determine the depth used during the process was correlated to the major true strain values $(\phi 1)$ applied to the sheet.
The first stage involved finding the material rupture depth (\#A); this workpiece was not used for the ISF process. The second stage involves the penetration of the punch nearly to the point of rupture in the workpiece $(\# B)$. The third and fourth stages were performed when the central element values reached $\phi 1=0.10(\# C)$ and $\phi 1$ $=0.05$ (\#D) in the strain sheet for the workpiece.

To define the die displacement during the process and reach the stop criteria for experiments \#C and \#D, some interpolations were performed between simulated and real data.

The simulated data was extracted using a $2 \mathrm{~mm}$ die displacement; however, the experimental data were extracted from a workpiece with a \#A stop criteria. Consequently, the major true strain data for the element and the die displacement were used to interpolate the data and create the experimental strain path for the central element. Figure 7 compares the strain paths of the simulated and experimental major true strain in the samples.

By using the major true strain path experimental curve, the stop criteria for the conventional experiments could be defined through the die displacement. In Table 2, the simulated and experimental data for the first stage are shown, and the die displacement (depth) is defined relative to the simulated data.

\subsubsection{Incremental Sheet Forming-ISF}

The incremental forming (SPIF) process was equally applied for every formed sheet sample. The process depends on several parameters, such as tool-size and lubricant, but toolpath plays a major role. In this sense, to guarantee that the toolpath strategy does not interfere with the pre-strain evaluation, and to keep a feasible number of different experiments, step-down, travel speed and geometry were fixed for all tests. In Figure 8,

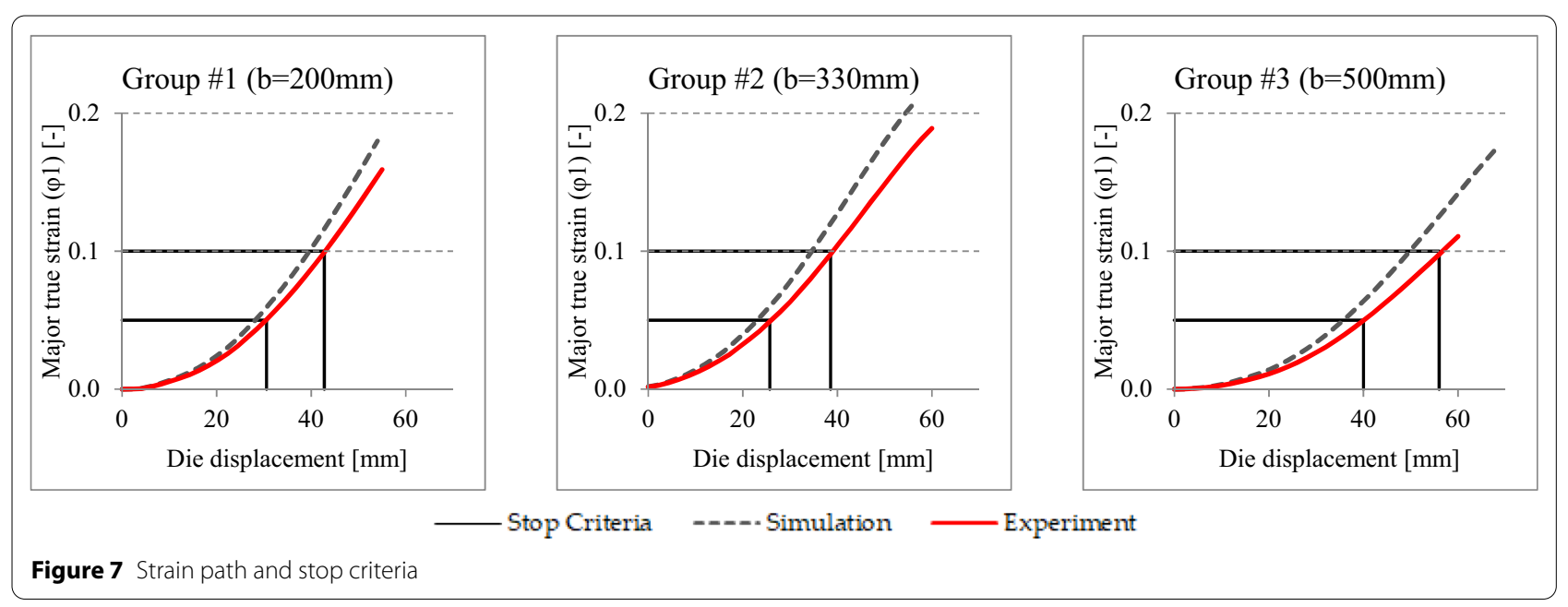




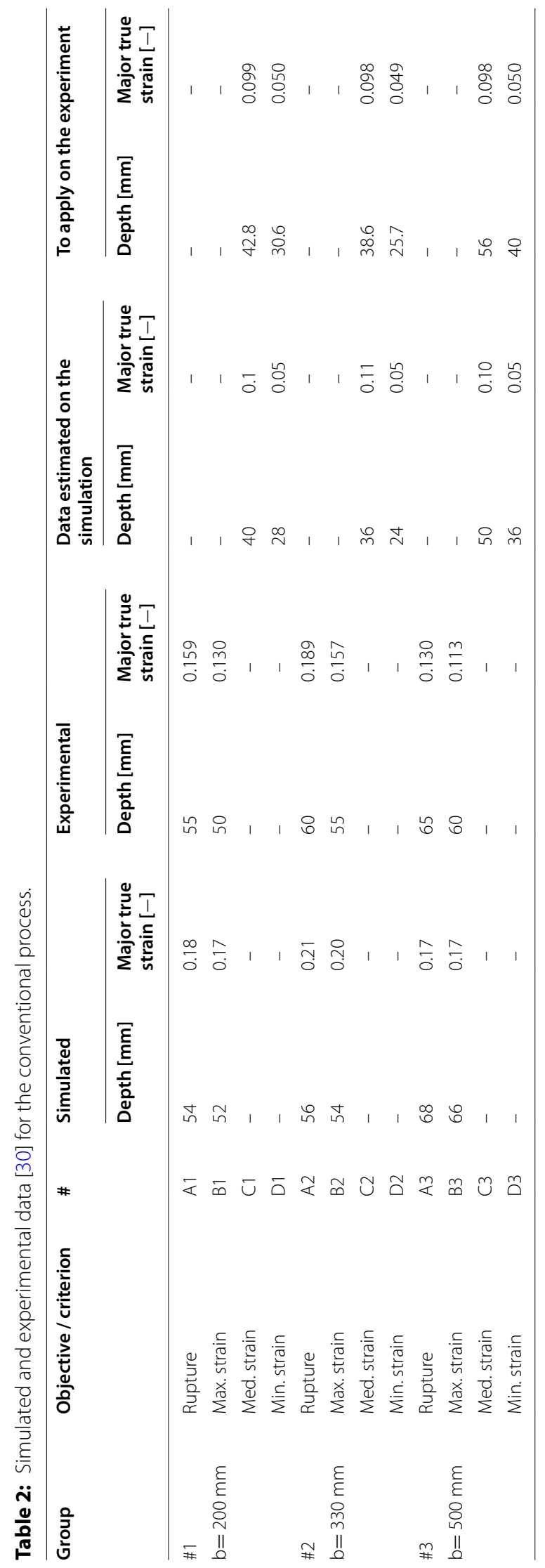




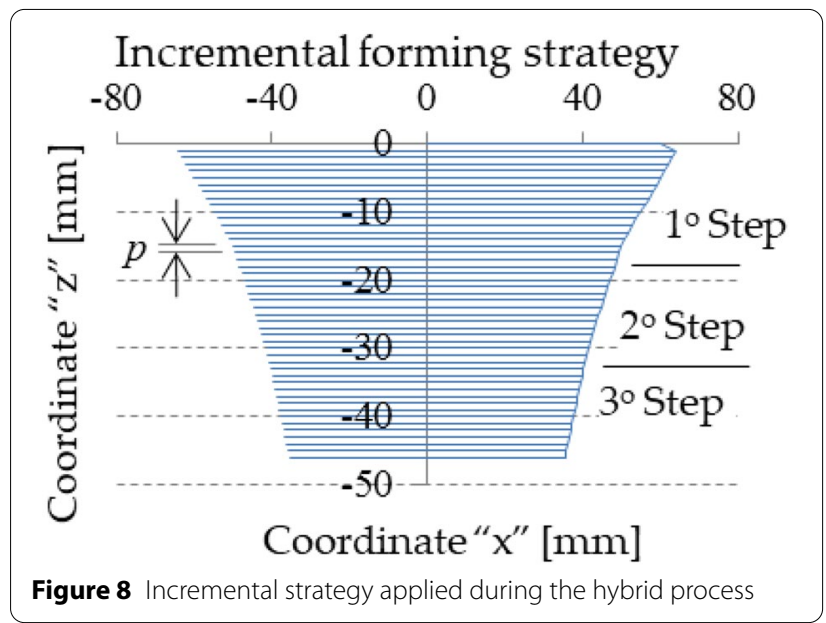

the chosen toolpath for the experiments is displayed, using a pyramidal geometry with a $128 \times 128 \mathrm{~mm}^{2}$ base, a 450 incline in the wall for the first $15 \mathrm{~mm}$ (10 step), a 600 incline from 15 to $30 \mathrm{~mm}$ (20 step) and a 700 incline up to the point of material rupture (30 step). A hemispherical punch with diameter $20 \mathrm{~mm}$ underwent a travel speed of $2000 \mathrm{~mm} / \mathrm{min}$ and a vertical step-down increment of $1 \mathrm{~mm}(\mathrm{p})$. A pyramidal geometry was adopted for the incremental process strategy because the strains are imposed in the direction of one side of the pyramid (edges); only the major true strain relationship will be analyzed.

The tests were carried out using a SPIF negative variant; the punch solely makes contact with the strained sheet area. Figure 9 shows how the tooling was inserted into the DLNC RB AMINO equipment.

The tests were interrupted when a rupture/rip appeared. They were repeated three times each. For every test, the cracks happened at the third stage, when the wall slope reached 700. In Figure 10a, the final sample geometry (\#B3) is showed, while in picture 10b, the central sheet point ("O") and its $x, y$ coordinates are depicted. Punch increments can be found at Region A (where " $x$ " is positive), while Region B (where " $x$ " is negative and “ $y=0 "$ ") was employed to investigate the major true strain numbers.

\section{Results and Discussion}

\subsection{Conventional Forming}

The first phase of the herein studied hybrid process is conventional forming. The evaluation was carried out focusing on the strains developed at the sheet center. Figure 11 shows the physical sheet shape and in Figures 12 and 13, the higher true strains along the " $x$ " direction as well as the central zone strains in the forming

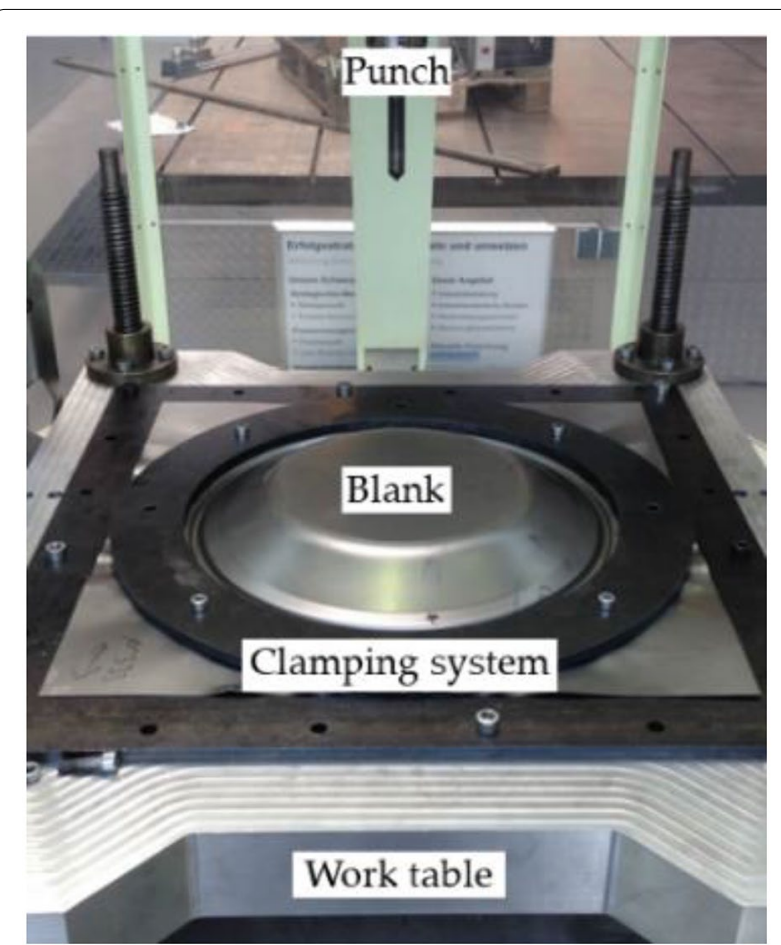

Figure 9 Incremental process setup

(fracture-based, [11]) diagram (the average values of the three tested specimens) are observed.

According to Figure 12, the three stop criteria used for the stretching trials, and linked to the highest found true strain, were attained. In group \# B3, the formed sheet reached 0.11 (major true strain), which the highest deformation at the central zone $(x=0 \mathrm{~mm})$; in test \#C3, 0.10 was reached, and in test \#D3, 0.05 was reached (averaged values).

With a bigger difference than the other groups, the sample group \#2 obtained $\phi 1$ also lower than expected for the stop criteria. The scope of pre-strain (minor true strain- $\phi 2$ : $[-0.13 ; 0.11]$ ) is observed in the strain diagram, where the sample with smaller width encompassed strains of the left side of the diagram (quadrant 2), while the strains of group \#3 covered the right side (quadrant 1).

Table 3 shows the experimental and simulated strain for the conventional process of the core element of samples used as a stop criterion. In the simulation, the stop criterion for the punch displacement was the pre-defined depth in relation to experimental data.

\subsection{Incremental Sheet Forming}

The pyramidal geometry incremental strategy was applied to the superior region of the workpiece and the dimensions of the incremental cavity limited the 

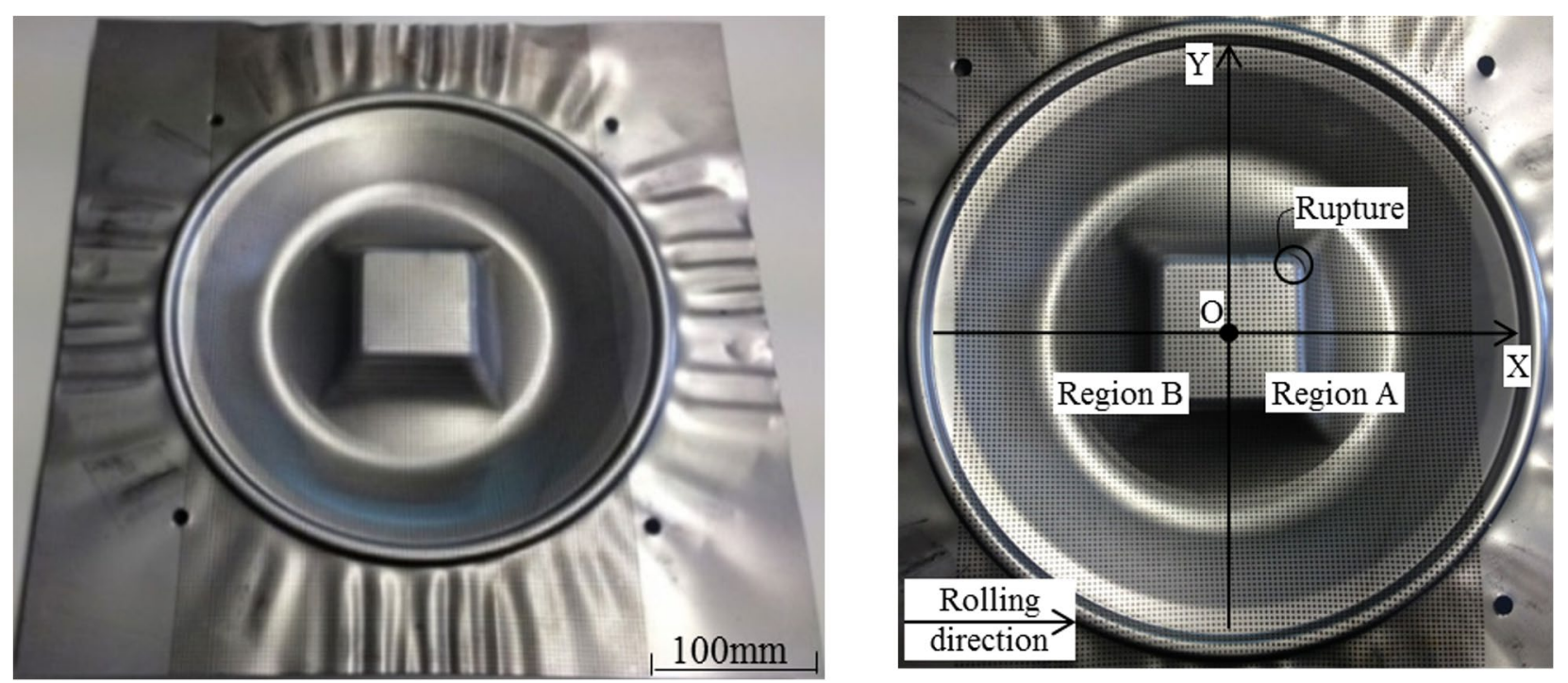

Figure 10 a Forming a sheet metal using the hybrid forming; b Coordinates used for the foring analysis

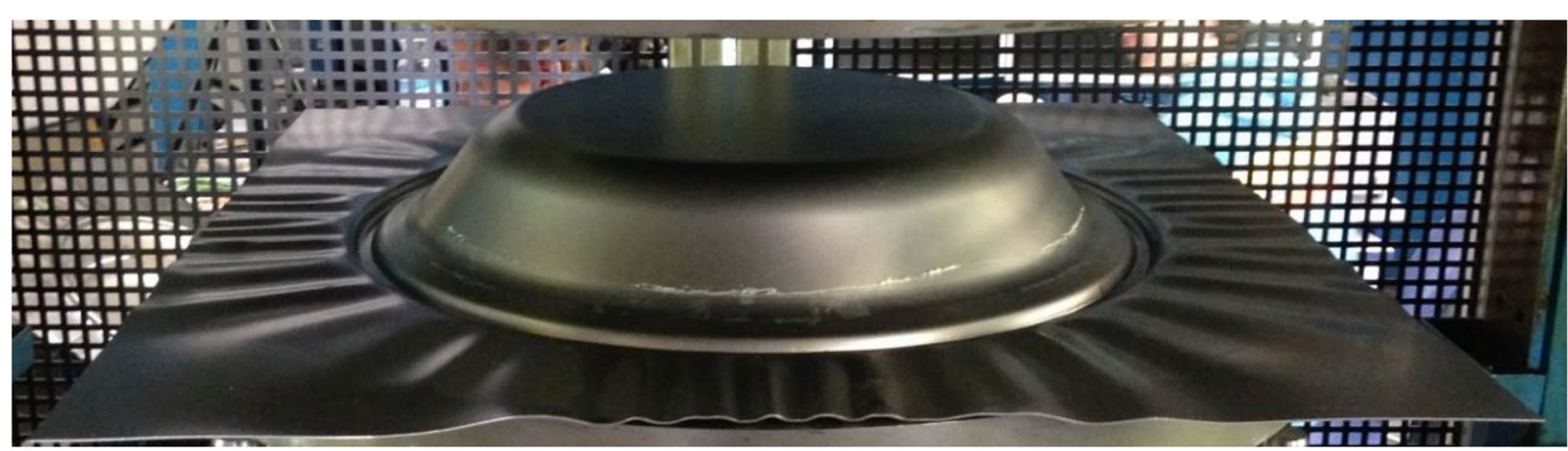

Figure 11 Physical sheet shape after conventional process from sample \#B3
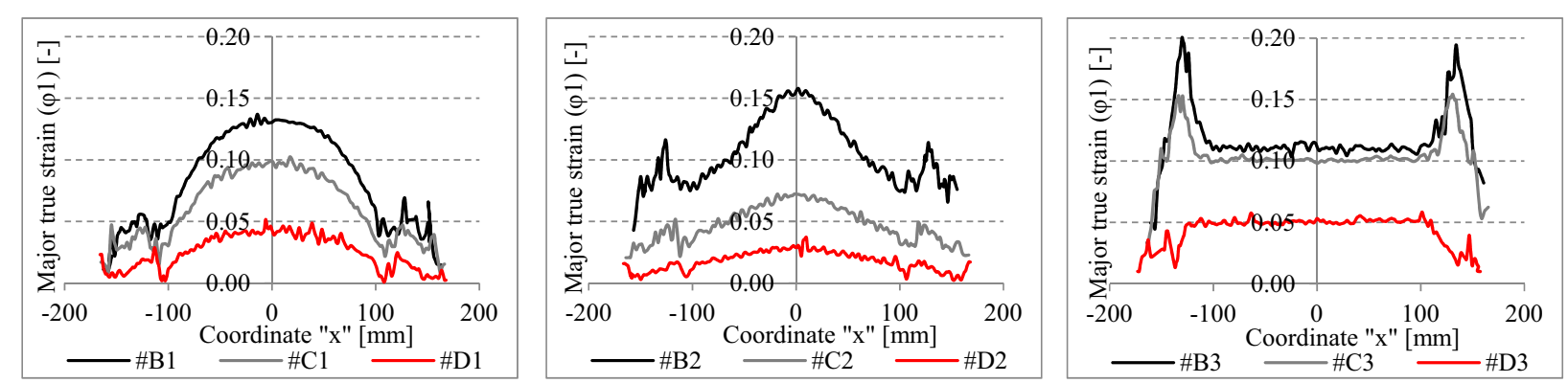

Figure 12 Major experimental true strains found along the " $x$ " axis

dimensions of the pyramidal edges. In Figure 14, the samples formed by the hybrid process of group \#1, \#2 and \#3 can be observed. The samples were formed by the incremental process until rupture which was visually inspected.

In Figure 15, through a central cut, the final geometry of the workpiece from test group \#3 is observed and the 


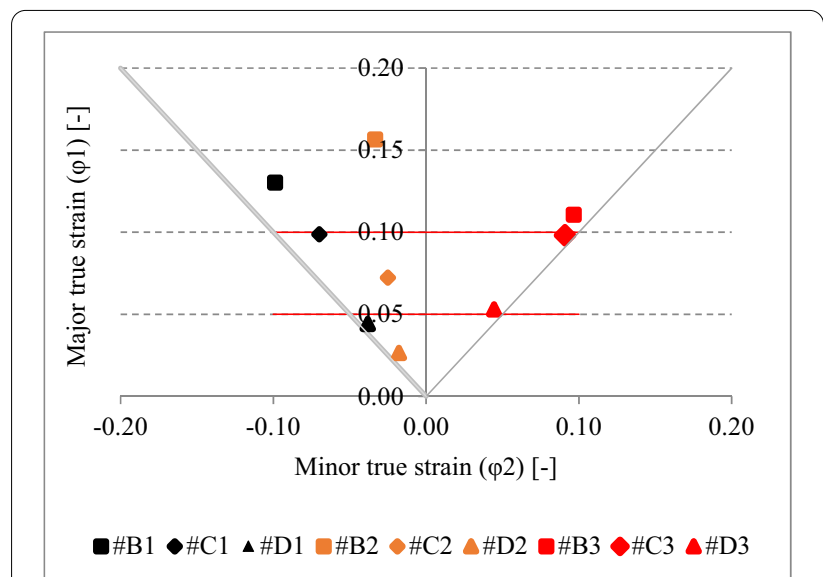

Figure 13 The central element forming strain

area analyzed. A bend region in the ends of the incremental cavity and the pyramidal wall inclinations are also observed. The objective of applying the incremental strategy with three different inclines was to reduce the workpiece bending effect in the final pre-strain evaluation. In the first stage (450 slope) there is bending near the incremental process, and in the second stage at 600 , bending occurs at the wall stabilization. Consequently, the third stage at 700 ruptured the sample.

Region (B) contains the area where the last deformation values were attained when forming the sheets via the hybrid process. These strains were computed in Figure $10 \mathrm{~b}$, since no punch increment in nor sample rupture was noticed. In Figure 16, results from the simulated forming paths were plotted in the forming graph, regarding the elements located at the 700 slopped wall. They achieved the biggest value in terms of major true strains during the whole hybrid process. There are variations in the values of the major true strain between the central

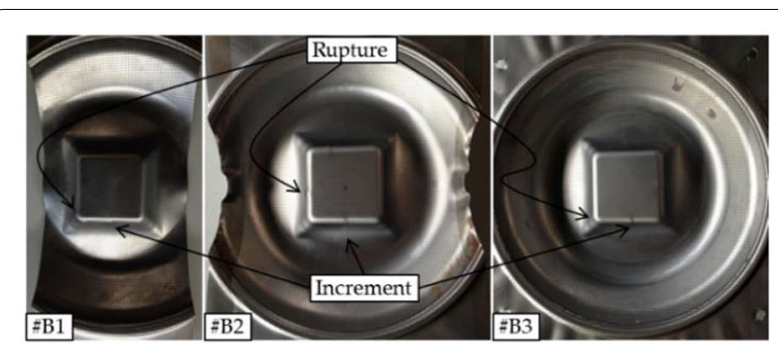

Figure 14 Samples formed through hybrid process

elements used as the stop criteria and the elements subjected to the incremental process; however, this difference might be appalling due to its magnitude.

Figure 17 displays the maximum strains attained at the sample side wall; such strains preferably appeared oppositely to the increment formed by the punch. In Figure 17, the forming paths are perceived looking to the forming curve for the sheet formed via the hybrid process. Each test result is characterized by averaging the three trials. The measured forming paths are comparable to the numerical results, including the final trend of the major true strains.

Table 4 depicts the values of the strains in conventional steps and at the end of the hybrid process, the elements with the greatest major true strains $(\phi 1)$. It is possible to analyze, through the data on minor true strain, that the variations applied by the incremental process is minimal, i.e., the incremental strategy adopted applied strains in only one direction, as anticipated. This way, the analysis is focused on major true strain paths.

Furthermore, the relationship between the different processes can be discussed based on the forming diagrams of Figure 18. As typical from incremental forming, the SPIF line does not reach the second quadrant of the deformation diagram, which can only be achieved

Table 3 Strains in the conventional process.

\begin{tabular}{|c|c|c|c|c|c|c|}
\hline \multirow[t]{2}{*}{ Group } & \multirow[t]{2}{*}{$\#$} & \multirow[t]{2}{*}{ Goal } & \multicolumn{2}{|l|}{ Experimental } & \multicolumn{2}{|l|}{ Simulated } \\
\hline & & & Major true strain & Minor true strain & Major true strain & $\begin{array}{l}\text { Minor true } \\
\text { strain }\end{array}$ \\
\hline \multirow[t]{3}{*}{1} & B1 & Max. Strain & 0.130 & -0.099 & 0.13 & -0.09 \\
\hline & $\mathrm{C} 1$ & Med. Strain & 0.099 & -0.070 & 0.10 & -0.07 \\
\hline & D1 & Min. Strain & 0.044 & -0.038 & 0.05 & -0.04 \\
\hline \multirow[t]{3}{*}{2} & B2 & Max. Strain & 0.157 & -0.033 & 0.15 & -0.02 \\
\hline & $\mathrm{C} 2$ & Med. Strain & 0.072 & -0.025 & 0.08 & -0.01 \\
\hline & D2 & Min. Strain & 0.027 & -0.018 & 0.03 & 0.00 \\
\hline \multirow[t]{3}{*}{3} & B3 & Max. Strain & 0.111 & 0.097 & 0.12 & 0.13 \\
\hline & $\mathrm{C} 3$ & Med. Strain & 0.098 & 0.091 & 0.11 & 0.11 \\
\hline & D3 & Min. Strain & 0.053 & 0.044 & 0.06 & 0.06 \\
\hline
\end{tabular}




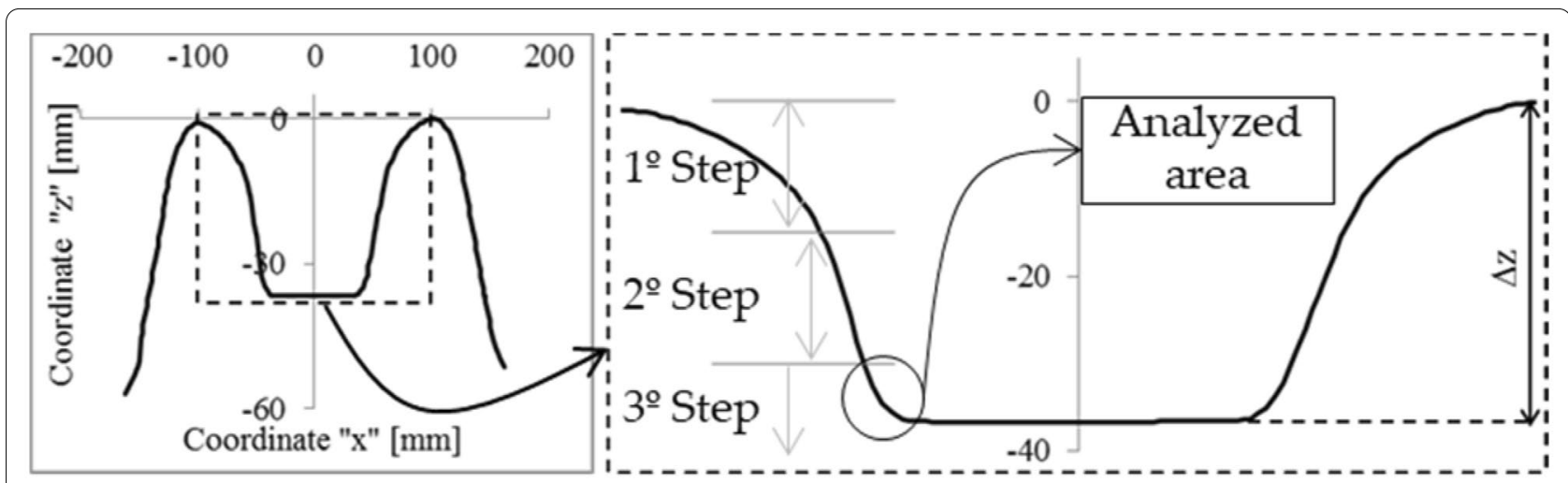

Figure 15 Final geometry of the workpiece formed with the hybrid process
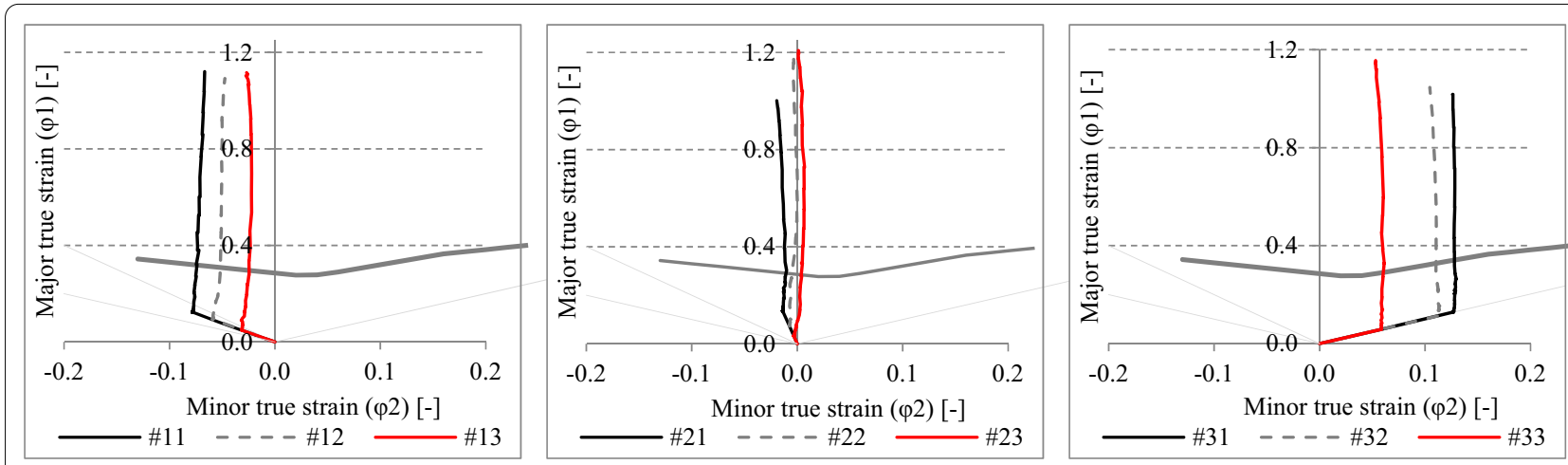

Figure 16 Forming paths (simulated) using the depth stop criteria
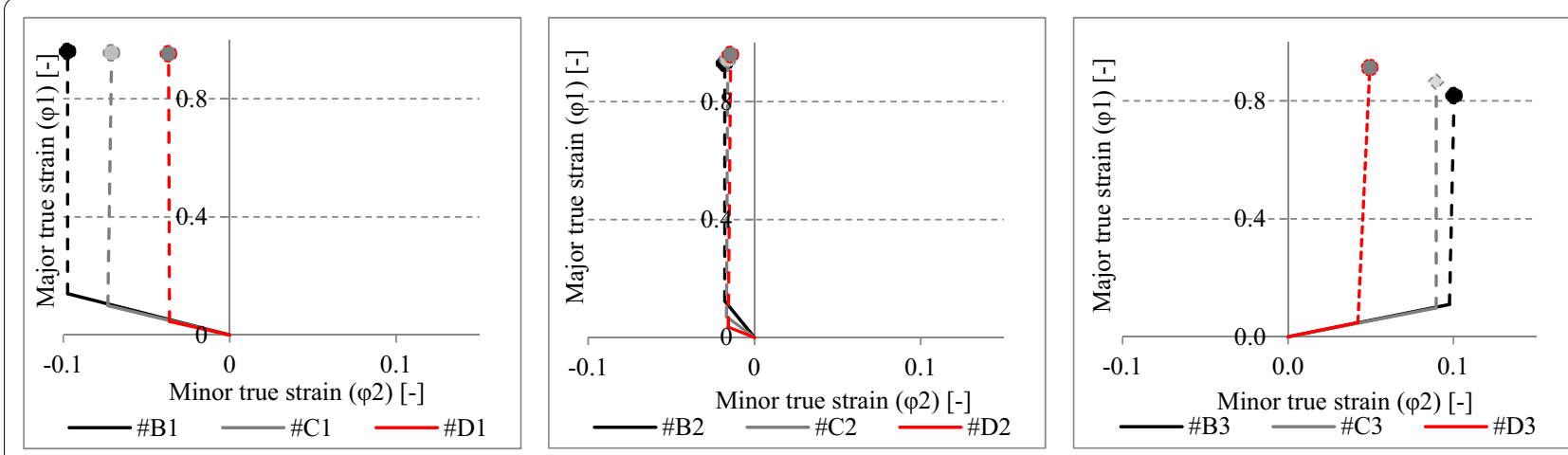

Figure 17 Forming paths (experimental) during the hybrid process

by pre-forming the part using the conventional process. Bearing this in mind, it is difficult to directly compare hybrid with pure SPIF processes, since the latter results only in deformations in the first quadrant.

Thus, one can compare SPIF processes only when using group \# 3 of experiments, Figure 18, where the FLC is observed including the deformations resulting from the applied hybrid process $\left(\phi_{\max }=1.26\right)$, according to simulated data. Note that SPIF is able to get closer to the abscissa axis $(\phi 2)$, however, in the hybrid process there is a more homogeneous strain distribution.

\section{Conclusions}

The investigation carried out can lead to the following conclusions: 
Table 4 Strains simulated in the hybrid process steps.

\begin{tabular}{|c|c|c|c|c|}
\hline \multirow[t]{3}{*}{ Experiment } & \multicolumn{4}{|c|}{ True strain } \\
\hline & \multicolumn{2}{|c|}{ Conventional process } & \multicolumn{2}{|c|}{ Final hybrid process } \\
\hline & Minor & Major & Minor & Major \\
\hline \#B1 & -0.08 & 0.12 & -0.07 & 1.12 \\
\hline \#C1 & -0.06 & 0.09 & -0.05 & 1.09 \\
\hline \#D1 & -0.03 & 0.05 & -0.03 & 1.12 \\
\hline \#B2 & -0.01 & 0.14 & -0.02 & 1.00 \\
\hline \#C2 & -0.01 & 0.07 & 0.00 & 1.19 \\
\hline \#D2 & 0.00 & 0.03 & 0.00 & 1.21 \\
\hline \#B3 & 0.13 & 0.13 & 0.13 & 1.02 \\
\hline \#C3 & 0.11 & 0.11 & 0.10 & 1.05 \\
\hline \#D3 & 0.06 & 0.06 & 0.05 & 1.16 \\
\hline
\end{tabular}

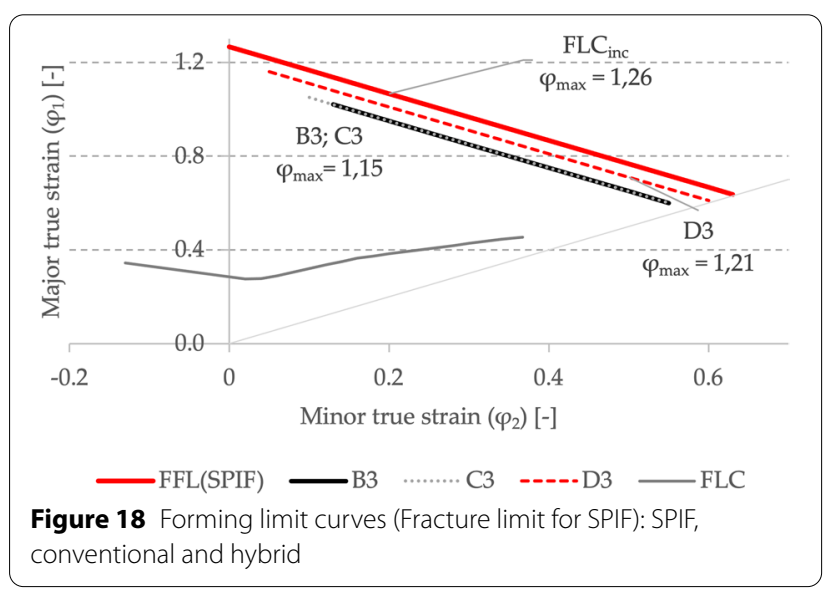

Pre-strains straightforwardly influences the maximum deformations attained during the hybrid forming process. The bigger the amount of pre-deformation (in terms of major true strain), and consequently accumulated hardening coming from the stretching process, the lower one can expect the resulting major true strain in the following incremental forming process. That conclusion is clear from the true strain values obtained in sample group \#3 (Table 4), being D3 the higher for $\phi_{1}$ and B3 the lowest at the end of the hybrid process. On the other hand, the pre-strain will reduce sample thickness and condition the incremental forming process (that heavily relies on stretching deformation mechanics).

The hybrid forming process made possible to manufacture the sheets with larger minor true strains, thus adding greater homogeneity to the formed sheets. Since ISF yields mainly planar deformations $\left(\phi_{2} \approx 0\right)$, design possibilities are further increased with hybrid forming strategies.

The strains coming from the hybrid forming process had greater coverage (1st and 2nd quadrant of the strain diagram) than the strains generated only by the incremental process. A better distribution of strains will lead to smoother stress gradients, more uniform hardening and less springback issues after the forming process.

The pre-strains coming from the second quadrant of the forming diagram (deep drawing) had a smaller influence on the following incremental strategy. That can be checked on Figures 16 and 17, sample group \#1; singlestretch pre-strain $\left(\phi_{2} \approx 0\right)$, which resembles ISF solely based strain path, has its influence minimized after the incremental forming counterpart of the hybrid process. Group \#2 of samples and Figure 17 exemplifies it.

\section{Acknowledgments}

Fabio Lora gratefully acknowledge LdTM/UFRGS, SENAI CIMATEC and IBF/ RWTH-Aachen for their support during the development of this work, as well as CAPES for financial support in the form of a scholarship. Daniel Fritzen acknowledges CNPq 234851/2014-7 (Doutorado Sanduíche no Exterior) SWE. Ricardo J. Alves de Sousa acknowledges grants UID/EMS/00481/2019FCT and CENTRO-01-0145-FEDER-022083-Centro2020, European Regional Development Fund (ERDF).

\section{Authors' contributions}

Writing-original draft preparation, FAL; Writing-review and editing, FAL, DF and RJAS; Supervision, LS; Funding acquisition, FAL and LS. All authors read and approved the final manuscript.

\section{Funding}

This research was support by CNPq/DAAD 2010-Doutorado no Exterior-GDE Grant Number 290096/2010-3 in the form of a scholarship.

\section{Availability of Data and Materials}

The datasets used and/or analysed during the current study are available from the corresponding author on reasonable request.

\section{Competing Interests}

The authors declare that they have no competing interests.

\section{Author Details}

${ }^{1}$ Department of Materials Engineering, Federal University of Recôncavo da Bahia, Campus CETENS, Feira de Santana, Bahia 44085-132, Brazil. ${ }^{2}$ SATC University, Criciuma, Brazil. ${ }^{3}$ Center of Mechanical Technology and Automation, Department of Mechanical Engineering, University of Aveiro, 3810-193 Aveiro, Portugal. ${ }^{4}$ Federal University of Rio Grande do Sul, Porto Alegre, Brazil.

Received: 14 March 2020 Revised: 5 February 2021 Accepted: 28 April 2021

Published online: 11 May 2021

\section{References}

[1] E Leszak. Apparatus and process for incremental dieless forming. 1967, Patent US3342051A1.

[2] J Jeswiet, F Micari, G Hirt, et al. Asymmetric single point incremental forming of sheet metal. CIRP Annals Manufacturing Technology, 2005, 54: 88-114. https://doi.org/10.1016/S0007-8506(07)60021-3

[3] A K Behera, R A de Sousa, G Ingarao, et al. Single point incremental forming: An assessment of the progress and technology trends from 2005 to 2015. Journal of Manufacturing Processes, 2017, 27: 37-62, https://doi.org/ 10.1016/j.jmapro.2017.03.014.

[4] R Malhotra, L Xue, T Belytschko, et al. Mechanics of fracture in single point incremental forming. Journal of Materials Processing Technology, 2012, 212: 1573-1590, https://doi.org/10.1016/j.jmatprotec.2012.02.021.

[5] Y Fang, B Lu, J Chen, et al. Analytical and experimental investigations on deformation mechanism and fracture behavior in single point 
incremental forming. Journal of Materials Processing Technology, 2014, 214: 1503-1515, https://doi.org/10.1016/.jmatprotec.2014.02.019.

[6] D Fritzen, A Daleffe, do Santos De Lucca, et al. Incremental forming of Cu-35Zn brass alloy. International Journal of Material Forming, 2018, 11 (3): 389-404, https://doi.org/10.1007/s12289-017-1373-4.

[7] M B Silva, M Skjoedt, A G Atkins, et al. Single point incremental forming and formability - failure diagrams. The Journal of Strain Analysis for Engineering Design, 2008, 43(1): 15-35. https://doi.org/10.1243/03093247JS A340.

[8] J Jeswiet, D Young. Forming limit diagrams for single-point incremental forming of aluminium sheet. Proceedings of the Institution of Mechanical Engineers, Part B: Journal of Engineering Manufacture, 2005, 219: 359-364, https://doi.org/10.1243/095440505X32210.

[9] R N Pereira Bastos, R J Alves de Sousa, J A Fernandes Ferreira. Enhancing time efficiency on single point incremental forming processes. International Journal of Material Forming, 2016, 9(5): 653-662, https://doi.org/10 1007/s12289-015-1251-X.

[10] G Hussain, L Gao, N Hayat, et al. A new formability indicator in single point incremental forming. Journal of Materials Processing Technology, 2009, 209: 4237-4242, https://doi.org/10.1016/j.jmatprotec.2008.11.024.

[11] K Isik, M B Silva, A E Tekkaya, et al. Formability limits by fracture in sheet metal forming. Journal of Materials Processing Technology, 2014, 214(8): 1557-1565, https://doi.org/10.1016/j.jmatprotec.2014.02.026. 9-4601-8210-5.

[12] W C Emmens, A Van den Boogaard. Strain in shear, and material behaviour in incremental forming. Key Engineering Materials, 2007, 344: 519-526, https://doi.org/10.4028/www.scientific.net/KEM.344.519.

[13] Y Kim, J Park. Effect of process parameters on formability in incremental forming of sheet metal. Journal of Materials Processing Technology, 2002, 130-131: 42-46, https://doi.org/10.1016/50924-0136(02)00788-4.

[14] $\mathrm{M} \mathrm{Ham}$, J Jeswiet. Single point incremental forming and the forming criteria for AA3003. CIRP Annals, 2006, 55: 241-244, https://doi.org/10.1016/ S0007-8506(07)60407-7.

[15] W Emmens, A Van den Boogaard. An overview of stabilizing deformation mechanisms in incremental sheet forming. Journal of Materials Processing Technology, 2009, 209: 3688-3695, https://doi.org/10.1016/j.jmatprotec. 2008.10.003.

[16] W C Emmens, G Sebastiani, A H Van den Boogaard. The technology of incremental sheet forming - A brief review of the history. Journal of Materials Processing Technology, 2010, 210: 981-997, https://doi.org/10.1016/j. jmatprotec.2010.02.014.

[17] M Bambach, G Hirt, J Ames. Modeling of optimization strategies in the incremental CNC sheet metal forming. Proceeding of 8th Numiform Conference, Columbus/Ohio, USA, 13-17 June 2004, https://doi.org/10. 1063/1.1766822.

[18] J Ames. Systematische Untersuchung der Beeinflussung des Werkstoffflusses bei der Inkrementellen Blechumformung mit CNC-Werkzeugmaschinen. Shaker: Aachen, Germany, Umformtechnische Schriften, 2008.
[19] Taleb Araghi, B. Inkrementelle Blechumformung und ihre Kombination mit Streckziehen - Grundlagen und Anwendungen. Shaker: Aachen, Germany, Umformtechnische Schriften, 2012.

[20] L Filice, L Fratini, F Micari. Analysis of material formability in incremental forming. CIRP Annals, 2002, 51: 199-202, https://doi.org/10.1016/S00078506(07)61499-1.

[21] L Fratini, G Ambrogio, R Di Lorenzo, et al. Influence of mechanical properties of the sheet material on formability in single point incremental forming. CIRP Annals, 2004, 53: 207-210, https://doi.org/10.1016/S00078506(07)60680-5.

[22] J Allwood, D Shouler, A ETekkaya. The increased forming limits of incremental sheet forming processes. Key Engineering Materials, 2007, 344: 621-628, https://doi.org/10.4028/www.scientific.net/KEM.344.621.

[23] T Kim, D Yang. Improvement of formability for the incremental sheet metal forming process. International Journal of Mechanical Sciences, 2000, 42: 1271-1286, https://doi.org/10.1016/S0020-7403(99)00047-8.

[24] M Silva, M Skjødt, P A Martins, N. Bay, Revisiting the fundamentals of single point incremental forming by means of membrane analysis. International Journal of Machine Tools and Manufacture, 2008, 48: 73-83, https://doi.org/10.1016/j.jimachtools.2007.07.004.

[25] B Taleb Araghi, M Bambach, G Hirt, et al. Investigations into the process mechanics of the hybrid process combination of stretch forming and incremental sheet forming. Steel Research Internatinal, Special Edition: 10th International Conference on Technology of Plasticity (ICTP), Aachen, Germany, 25-30 September, 2011: 519-524.

[26] B Taleb Araghi, G L Manco, M Bambach, et al. Investigation into a new hybrid forming process: Incremental sheet forming combined with stretch forming. CIRP Annals, 2009, 58: 225-228, https://doi.org/10.1016/j. cirp.2009.03.101.

[27] S Dejardin, S Thibaud, J C Gelin, et al. Experimental investigations and numerical analysis for improving knowledge of incremental sheet forming process for sheet metal parts. Journal of Materials Processing Technology, 2010, 210: 363-369, https://doi.org/10.1016/j.jmatprotec.2009.09.025.

[28] J Lian, F Barlat, B Baudelet. Plastic behaviour and stretchability of sheet metals. Part I: A yield function for orthotropic sheets under plane stress conditions. International Journal of Plasticity, 1989, 5: 51-66, https://doi. org/10.1016/0749-6419(89)90019-3.

[29] K Rah, WV Paepegem, A M Habraken, et al. Optimal low-order fully integrated solid-shell elements. Computational Mechanics, 2013, 51(3): 309-326.

[30] F A Lora. Deformation assessment in DC04 steel when subjected to the incremental stamping hybrid process after the conventional process. PhD thesis (in portuguese): Porto Alegre, Brazil (2014). http://hdl.handle.net/ 10183/103731.

[31] B Taleb Araghi, G L Manco, M Bambach, et al. Investigation into a new hybrid forming process: Incremental sheet forming combined with stretch forming. CIRP Annals, 2009, 58(1): 225-228, https://doi.org/10. 1016/j.cirp.2009.03.101.

\section{Submit your manuscript to a SpringerOpen ${ }^{\odot}$ journal and benefit from:}

- Convenient online submission

- Rigorous peer review

- Open access: articles freely available online

- High visibility within the field

- Retaining the copyright to your article

Submit your next manuscript at $\boldsymbol{\nabla}$ springeropen.com 